J. Lake Sci.(湖泊科学), 2008, 20(3): 351-356

http://www.jlakes.org. E-mail: jlakes@niglas.ac.cn

(C)2008 by Journal of Lake Sciences

\title{
惠州西湖浮游动物及其与水质的关系*
}

陈光荣, 钟 萍, 张修峰, 谢贻发, 李传红

(暨南大学水生生物研究所, 广州 510632)

摘 要: 通过对惠州西湖五个子湖的浮游动物情况进行调查, 共检出浮游动物 55 种, 其中轮虫 38 种, 枝角类 10 种, 桡足类 7 种, 主要优势种为广生多肢轮虫(Polyarthra trigla)、长三肢轮虫(Filinia longiseta)、裂足臂尾轮虫(Brachionus diversicornis)、 剪形臂尾轮虫(B. forficula)、角突臂尾轮虫(B. angularis)、蓦花臂尾轮虫(B. calyciflorus)、前节晶囊轮虫(Asplanchna priodonta)、 刺盖异尾轮虫(T. capucina)、微型裸腹溞(Moina micrura)、温中剑水蚤(Mesocyclops thermocyclopoides)等, 多为富营养化指示 种, 各子湖浮游动物检出丰度处于 147.3 到 726.1 ind./L 之间, 其中轮虫丰度占据优势, 浮游动物趋向小型化, 结合浮游动物丰 度与水质指标进行相关分析结果表明, 浮游动物的分布情况与水体水质特征关系密切.

关键词: 惠州西湖; 浮游动物; 水质

\section{Zooplankton and its relationship with water quality in Huizhou West Lake}

CHEN Guangrong, ZHONG Ping, ZHANG Xiufeng, XIE Yifa \& LI Chuanhong

(Institute of Hydrobiology, Jinan University, Guangzhou 510632, P.R.China)

\begin{abstract}
Abastract: Investigation on the zooplankton of Huizhou West Lake which composed of five small connected lakes were carried out for three times from January to September 2005. 55 species of zooplankton including 38 species of Rotifers, 10 species of Cladocerans and 7 species of Copepods were found. The dominant species included Polyarthra trigla, Filinia longiseta, Brachionus diversicornis, B. forficula, B. angularis, B. calyciflorus, Asplanchna priodonta, Trichocerca capucina, Moina micrura and Mesocyclops thermocyclopoides which mostly were the indicator species of eutrophication. The abundance of zooplankton were between 147.3and 726.10ind./L and the abundance of Rotifer were on predominance. It showed that the distribution of zooplankton were related closely to the water quality combined with correlative analysis of abundance of zooplankton and chemical and physical index of water.
\end{abstract}

Keywords: Huizhou West Lake; zooplankton; water quality

浮游动物作为次级生产力在水生态系统中起着重要的作用, 同时一些浮游动物对环境污染极为敏感, 因而浮游动物的生态学研究备受关注，对温带及热带的一些淡水水体浮游动物比较分析表明热带浮游动 物具备一些独特的特征, 如热带水体浮游动物多样性趋低, 种类数量减少，同时趋向小型种群，大型的 枝角类在温带很常见而在热带则分布较少 ${ }^{[1-2]}$, 热带亚热带浮游动物以轮虫、小型枝角类、无节桡足幼体 为主 ${ }^{[3-4]}$, 而小型的浮游动物不利于对水体浮游植物的控制. 水体中浮游动物的数量消长除了与其它环境 因素有关外, 与水质污染的程度密切相关, 利用浮游动物群落结构的综合指标(种类组成差异、种类数目 变化、个体数量变动及生物量分布、多样性指数的增减)可以检测评价水质及变化趋势 $[5-6]$, 在广范围的温 带一热带湖泊, 随着营养上升, 浮游动物的密度也上升, 且小型种类有时也会上升 ${ }^{[7]}$. 热带水体浮游动物 分布的原因及其与水体水质的关系有待于进一步的研究.

惠州西湖是典型的热带浅水城市湖泊(北纬 $23^{\circ} 15^{\prime}$, 东经 $114^{\circ} 37^{\prime}$ ), 由南湖、丰湖、平湖、鳐湖和菱湖

\footnotetext{
*广东省科技计划项目(2006B36703003)资助. 2007-04-28 收稿; 2007-10-08 收修改稿. 陈光荣, 男, 1978 年生, 博士, 讲师;
} E-mail: cgr@hunau.edu.cn. 

组成, 湖面面积 $1.48 \mathrm{~km}^{2}$, 湖水平均深度 $1.6 \mathrm{~m}$ 左右. 随着惠州市经济的发展, 西湖富营养化程度加剧, 影 响了水体的服务功能. 通过近几年的沉积物疏浚、城市污水截流和换水等工程措施，惠州西湖水体总氮 和总磷有所下降, 但由于湖泊生态系统退化、湖底污染物释放及其它污染物的排入等原因, 湖水的透明 度等指标没有得到根本改善, 仍处于富营养化状态. 本文通过对惠州西湖浮游动物的调查研究, 有利于 了解热带浅水城市湖泊富营养化中浮游动物的群落结构特征, 为热带浅水城市富营养化湖泊生态恢复提 供一定的参考.

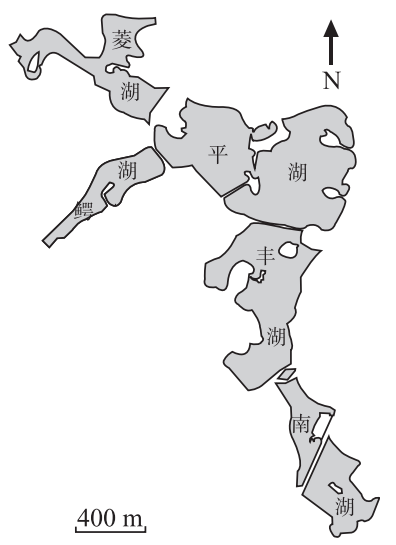

图 1 惠州西湖采样点位置

Fig.1 Sampling sites of Huizhou West Lake

\section{1 材料与方法}

\section{1 采样时间}

于 2005 年 1 月、 5 月、 9 月各采一次样, 采样点为惠州西湖各 子湖中心(图 1), 包括常规水质采样与分析 ${ }^{[8]}$.

\section{2 浮游动物定性定量采样与分析 $^{[9-12]}$}

轮虫定性用 25 号 $(64 \mu \mathrm{m})$ 浮游生物网拖取, 定量样品采水 $1 \mathrm{~L}$, 现 场加人 $5 \%$ 福尔马林固定, 带回实验室静置沉淀, 浓缩至 $30 \mathrm{ml}$ 在显 微镜下计数; 大型浮游动物定性用 13 号 $(113 \mu \mathrm{m})$ 拖取, 定量样品用 $5 \mathrm{~L}$ 采水器从表层水到底部采 25-50L, 用 25 号网过滤浓缩, 当场加 人 $5 \%$ 福尔马林固定. 定性样品在实验室用显微镜和解剖镜进行种 类鉴定, 定量样品在解剖镜下用 $1 \mathrm{ml}$ 计数框计数.

\section{2 结果与分析}

\section{1 浮游动物种类组成}

各子湖共检出浮游动物 55 种, 其中轮虫 11 科 38 种, 枝角类 10

种, 隶属于 7 科 9 属, 桡足类 7 种, 隶属于 3 科 7 属, 其中各子湖菱湖、平湖、鳄湖、丰湖、南湖检出种类 数分别为 34 种、 40 种、35 种、39 种、48 种, 以南湖和平湖出现种类相对较多，在种类上以臂尾轮属 $(10$ 种)和异尾轮属(6种)检出较多, 常见的检出种类有䒓花臂尾轮虫(Brachionus calyciflorus)、裂足臂尾轮虫 (B. diversicornis)、壸状臂尾轮虫 (B. urceus)、角突臂尾轮虫 (B.forficula)、剪形臂尾轮虫(B. angularis)、镰 状臂尾轮虫(B.falcatus)、裂痕龟纹轮虫(Anuraeopsis fissa)、前节晶囊轮虫(Asplanchna brightwelli)、下氏 晶囊轮虫 $(A$. priodonta)、纵长异尾轮虫 (Trichocerca elongata)、刺盖异尾轮虫 $(T$. capucina)、长三肢轮虫 (Filinia longiseta)、曲腿龟甲轮虫(Keratella valga)、尖尾疮毛轮虫(Synchaeta stylata)、广生多肢轮虫 (Polyarthra trigla)、独角聚花轮虫(Conochilus unicornis)、微型裸腹溞(Moina micrura)、角突网纹溞 (Ceriodaphnia cornuta)、台湾温剑水蚤 (Thermocyclops taihokuensis)、温中剑水蚤 (Mesocyclops thermocyclopoides)、小型后剑水蚤(Metacyclops minutus)等. 这些种类一般各子湖常年均可以看到. 总体来说, 浮游动物出现的种类数不多, 多以轮虫为主, 枝角类和桡足类出现的种类较少, 浮游动物趋向小型化.

\section{2 浮游动物丰度及优势种情况}

惠州西湖各子湖浮游动物丰度相差不大, 处于 147.30-726.10ind./L之间, 以菱湖和鳄湖丰度较高, 平 均分别为 470.57、431.03ind./L, 其次为丰湖各月平均 429.07ind./L, 平湖和南湖较低平均分别为 375.07 、 $354.57 \mathrm{ind} . / \mathrm{L}$, 在月份上, 各子湖平均丰度 1 月最低为 $283.66 \mathrm{ind} . / \mathrm{L}, 5$ 月和 9 月较高, 各子湖平均分别为 392.44、460.08ind./L, 其中轮虫丰度均占据总丰度的优势地位(图 2), 枝角类、桡足类等较大型浮游动物 丰度所占比例较低, 5 月份和 9 月份相比，轮虫丰度波动不大，而枝角类、桡足类 9 月份相对大幅增加(图 3). 惠州西湖各子湖浮游动物优势种类有萼花臂尾轮虫、裂足臂尾轮虫、剪形臂尾轮虫、角突臂尾轮虫、 卜氏晶囊轮虫、前节晶囊轮虫、广生多肢轮虫、长三肢轮虫、无节幼体等, 其中 1 月份各子湖主要以广 生多肢轮虫、䒓花臂尾轮虫、角突臂尾轮虫为主, 5 月份以卜氏晶囊轮虫、裂足臂尾轮虫、剪形臂尾轮虫 为主, 9 月份主要以裂足臂尾轮虫、长三肢轮虫为主, 优势种均为富营养化水体的指示种类, 且优势度较 大(图 4). 

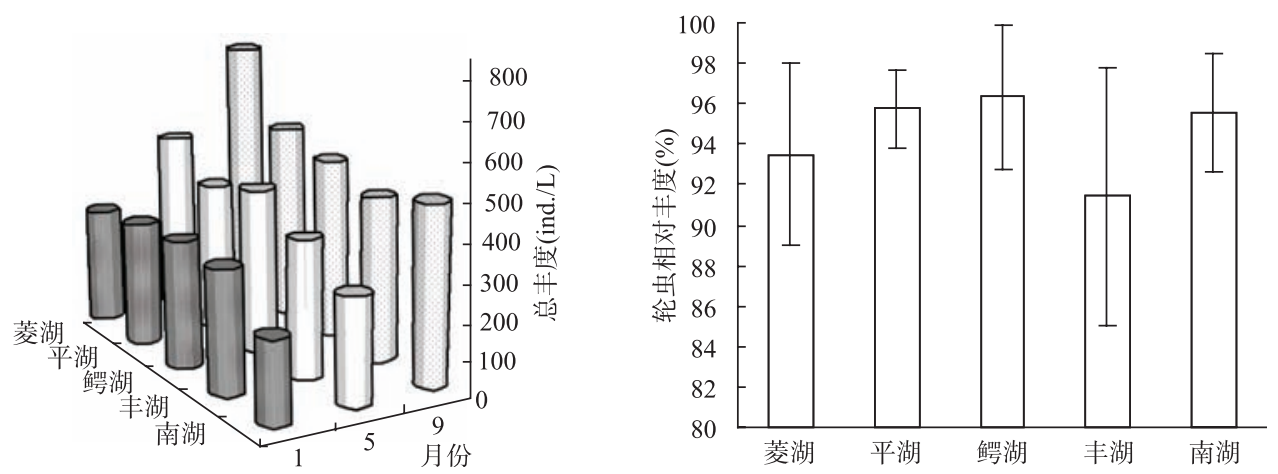

图 2 各子湖浮游动物丰度月份变化情况及轮虫的平均相对丰度 $( \pm \mathrm{SD})$

Fig.2 Zooplankton abundance in five lakes with different month and average relative abundance of rotifera
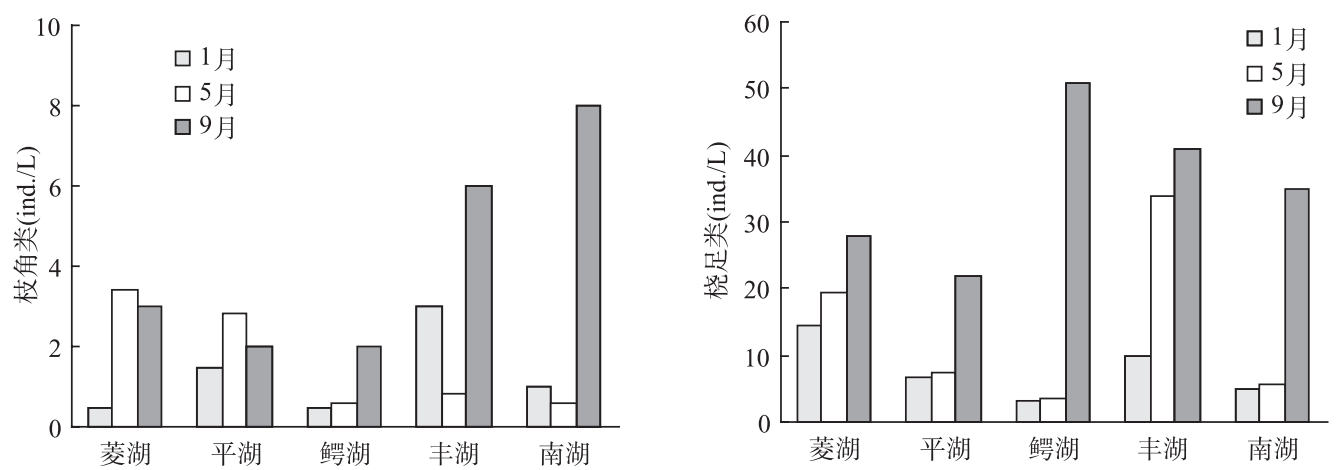

图 3 各子湖枝角类、桡足类丰度变化

Fig.3 The abundance of Cladocera and Copepoda in five lakes with different month

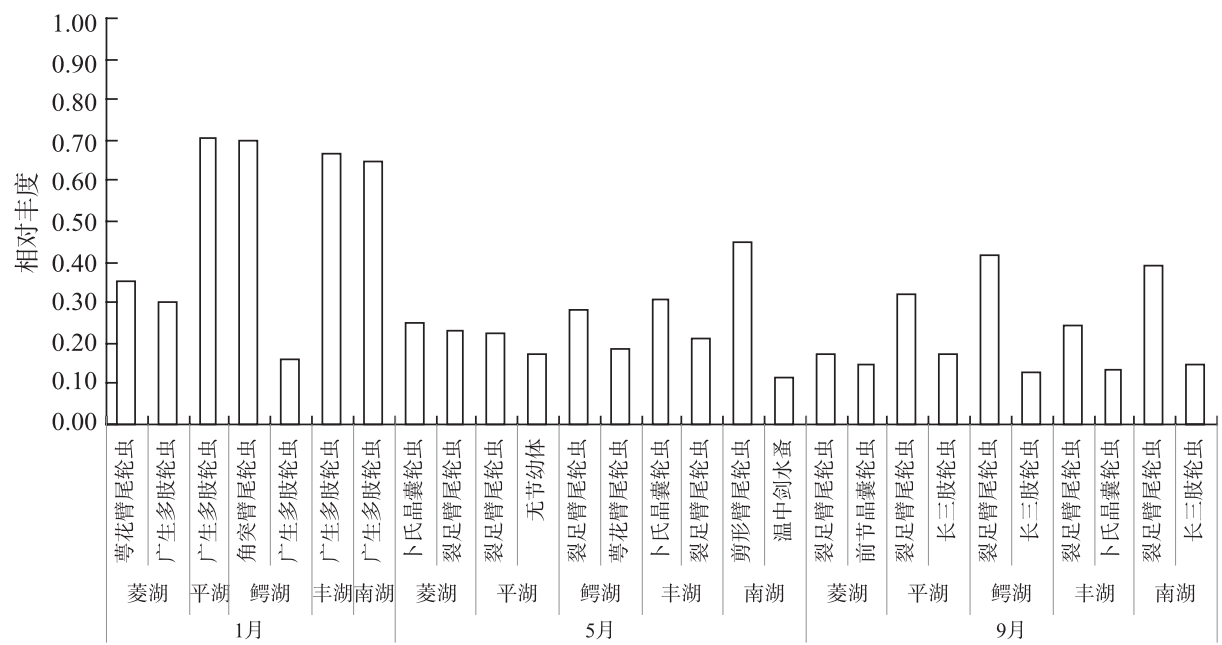

图 4 惠州西湖浮游动物优势种相对丰度

Fig.4 The relative abundance of dominant species of zooplankton in Huizhou West Lake 


\section{3 浮游动物丰度与水质因子相关分析}

惠州西湖各子湖水体水质因子各月平均值见表 1 , 其中以菱湖和䲞湖总磷含量及叶绿素含量较高, 悬浮物含量则以菱湖和平湖较高. 各子湖的浮游动物平均丰度与其水质指标均值相关分析如表 2 所示, 总体来看, 除了与透明度成负相关, 浮游动物总丰度与各项反应水体营养状况的重要指标基本成正相关, 尤其与叶绿素 $\mathrm{a}$ 、高锰酸盐指数、总磷的正相关系数较高, 其中小型浮游动物轮虫与县浮物浓度成正相关, 与透明度成负相关，而大型的枝角类、桡足类与悬浮物浓度成负相关，和透明度成正相关，这可能与惠州 西湖组成悬浮物的成分含有粒径较小的泥沙有关 ${ }^{[13]}$, 泥沙容易影响到大个体的浮游动物的摄食活动. 同 时, 富营养化水体中, 食物较丰富, 小型浮游动物如轮虫获得较大的竞争优势, 所以随着富营养化程度 加大，其丰度增加。

表 1 惠州西湖水质理化指标监测情况

Tab.1 The survey result of chemical and physical index in Huizhou West Lake

\begin{tabular}{ccccccccc}
\hline 项目 & $\begin{array}{c}\text { 总氮 } \\
(\mathrm{mg} / \mathrm{L})\end{array}$ & $\begin{array}{c}\text { 总磷 } \\
(\mathrm{mg} / \mathrm{L})\end{array}$ & $\begin{array}{c}\text { 化学需氧量 } \\
(\mathrm{mg} / \mathrm{L})\end{array}$ & $\begin{array}{c}\text { 叶绿素 } \\
(\mu \mathrm{g} / \mathrm{L})\end{array}$ & $\begin{array}{c}\text { 悬浮物 } \\
(\mathrm{mg} / \mathrm{L})\end{array}$ & $\begin{array}{c}\text { 透明度 } \\
(\mathrm{m})\end{array}$ & $\begin{array}{c}\text { 水温 } \\
\left({ }^{\circ} \mathrm{C}\right)\end{array}$ & $\mathrm{pH}$ \\
\hline 菱湖 & 1.812 & 0.129 & 7.74 & 102.61 & 34.22 & 0.27 & 27.4 & 8.03 \\
平湖 & 1.059 & 0.084 & 5.67 & 35.07 & 35.00 & 0.30 & 27.4 & 7.54 \\
鳄湖 & 1.098 & 0.107 & 6.66 & 87.56 & 29.52 & 0.28 & 27.5 & 7.69 \\
丰湖 & 1.168 & 0.078 & 6.20 & 51.46 & 29.00 & 0.35 & 27.7 & 8.31 \\
南湖 & 1.321 & 0.082 & 5.58 & 51.99 & 27.58 & 0.34 & 27.5 & 8.32 \\
\hline
\end{tabular}

表 2 浮游动物丰度与水质因子相关分析

Tab.2 The correlative analysis of chemical and physical index and abundance of zooplankton

\begin{tabular}{ccccccc}
\hline $\begin{array}{c}\text { 丰度 } \\
\text { (ind./L) }\end{array}$ & $\begin{array}{c}\text { 总氮 } \\
(\mathrm{mg} / \mathrm{L})\end{array}$ & $\begin{array}{c}\text { 总磷 } \\
(\mathrm{mg} / \mathrm{L})\end{array}$ & $\begin{array}{c}\text { 化学需氧量 } \\
(\mathrm{mg} / \mathrm{L})\end{array}$ & $\begin{array}{c}\text { 叶绿素 } \\
(\mu \mathrm{g} / \mathrm{L})\end{array}$ & $\begin{array}{c}\text { 悬浮物 } \\
(\mathrm{mg} / \mathrm{L})\end{array}$ & $\begin{array}{c}\text { 透明度 } \\
(\mathrm{m})\end{array}$ \\
\hline 轮虫 & 0.563 & 0.826 & $0.958^{*}$ & 0.841 & 0.340 & -0.642 \\
枝角类、桡足类 & 0.133 & -0.119 & 0.240 & 0.114 & -0.426 & 0.482 \\
总计 & 0.549 & 0.761 & $0.935^{*}$ & 0.808 & 0.262 & -0.538 \\
\hline
\end{tabular}

* 表示 0.05 显著水平相关(双尾检验).

\section{3 讨论与结论}

惠州西湖浮游动物采样中臂尾轮属、异尾轮属和腔轮属检出较多, 占总种数的 $41.5 \%$, 枝角类检出种 类少且丰度低，总的检出种类以广温性种类为主，兼具一些嗜暖种. 究其原因，其一与惠州西湖地处热 带有关, 水温是影响浮游动物生长、发育、群落组成和数量变化等极为重要的环境因子, 是影响浮游动 物水平分布的一个重要因素 ${ }^{[14-16]}$. 腔轮属、臂尾轮属和异尾轮属这 3 个属的种类集中分布于热带和亚热 带地区, 并占据了该地区轮虫种类组成的绝大部分 ${ }^{[17-20]}$, 在温带地区水体虽然也有分布, 但只有少数几 种; 龟甲轮属和疮毛轮属在热带和亚热带地区也有分布, 并且某些种类分布相当广泛或为该地区特有种, 但绝大多数种类主要分布于温带地区. 在浮游动物丰度分布上, 惠州西湖也以温度较高的 5 月份和 9 月 份总丰度较高, 据武汉东湖长期定点观测, 轮虫总数的高峰一般出现在 $20^{\circ} \mathrm{C}$ 以上的水温. 其中大型浮游 动物丰度 9 月较高, 可能 9 月水温较为适宜, 且水体中食物也较为丰富, Gillooly 和 Dodson ${ }^{[21]}$ 对温带和热 带水体比较分析得出, 当水体温度超过 $20^{\circ} \mathrm{C}$ 时, 溞属的数量通常很低. 其次, 鱼类的捕食也是影响浮游 动物群落结构和大小组成的原因之一，惠州西湖鱼类较多，包括鲢、鳙和罗非鱼等，除了养殖的鱼类外， 自然水体中的野杂鱼通常也具有很大的种群数量, 这些鱼类终年繁殖, 对浮游动物常年形成捕食压力. 鱼类的捕食对个体大小有明显的选择性, 通常在同等能耗下优先选择个体较大的浮游动物 ${ }^{[22]}$, 当鱼类密 
度高时, 个体较大的枝角类种类和丰度都很低 ${ }^{[23-24]}$, 鱼类的捕食行为在一定程度上减少了轮虫和小型枝 角类的种外竞争压力 ${ }^{[25-27]}$ ，因而种类组成和丰度上均以小型种类占绝对优势，而小型浮游动物对浮游植 物的控制能力小 ${ }^{[28]}$. 此外, 惠州西湖水体叶绿素含量较高, 水体富营养化比较严重, 浮游植物多以蓝绿 藻占据优势, 不利于枝角类等大型浮游动物的摄食, 小型轮虫变得相对重要, 进而使之成为水体的优势 类群. 总体来看, 较高的水温、鱼类的捕食压力较大、食物的限制等共同影响使得惠州西湖水体浮游动 物以轮虫、无节桡足幼体、小型枝角类为主.

惠州西湖浮游动物种类不多, 丰度较高, 其中一些耐污种占据种类和丰度的绝对优势, 对水体富营 养化污染程度有一定的指示作用. 研究表明, 在正常水体中 (清洁型水体), 浮游动物一般显示种类多, 数 量少的特点, 在重度污染(包括有机和重金属污染)的水体, 几乎所有的水生生物(除了少数种类的细菌)都 难以生存, 在较严重或中度富营养化的水体中, 往往是些耐污种类形成优势种群(以较高数量出现). 湖泊 生态系统中常见的浮游动物轮虫, 发育时间快, 生命周期短, 能较为迅速地反应环境的变化, 相对易于 采集, 被认为是好的指示生物, Maenets ${ }^{[29]}$ 指出轮虫可以分为三类主要的指示动物群: 贫中营养湖泊种 类、中富营养湖泊种类和富营养湖泊种类. Sladecek ${ }^{[30]}$ 对前捷克斯洛伐克附近的 620 种轮虫进行污染等级 的分类，分为异污性、塞污性、 $\beta$-中污性和 $\alpha$-中污性，异污性和塞污性的轮虫指示塞营养状态， $\beta$-中 污性和 $\alpha$-中污性轮虫指示富营养状态. 李明德 ${ }^{[1]}$ 指出污染等级不能单纯以轮虫的种类及数量为准, 还 需结合多刺裸腹溞、微小裸腹溞的有无、数量及水化学、水色、环境条件等具体分析. 惠州西湖检出的 常见种类臂尾轮虫、异尾轮虫、疮毛轮虫、长三肢轮虫、前节晶囊轮虫、多肢轮虫、螺形龟甲轮虫、微 型裸腹溞、温中剑水蚤等多被认为是富营养水体的指示种类 ${ }^{[5-6]}$. 当然, 各营养水平型水体中浮游动物的 组成不是绝然不同的，那些被认为是葟营养型的种类在中营养和富营养水体中也有分布，而被认为是富 营养型的种类同样在塞营养水体中有分布. 惠州西湖浮游动物种类少, 数量较大, 优势种多为富营养化 指示种，表明该湖处于富营养化状态，其中尤以菱湖、鲇湖种类较少而丰度较大，分布的种类主要为富营 养化指示种呈优势, 表明这两个子湖富营养化程度更高, 在南湖和平湖富营养化程度较轻, 均有少量塞 营养指示种出现, 这与水质指标分析结果一致.

\section{4 参考文献}

[1] Fernando $\mathrm{CH}$. The species and size composition of tropical freshwater zooplankton with special reference to the oriental region(South East Asia). Int Review Ges Hydrobiol, 1980, 76: 149-167.

[2] Fernando $\mathrm{CH}$. The freshwater zooplankton of Srilanka, with a discussion of tropical freshwater zooplankton compostion. Int Review Ges Hydrobiol, 1980, 65: 85-125.

[3] Branco CWC, Rocha MI, Pinto GFS et al. limnological features of Funil Reservoir(Brazil R J)and indicator properties of rotifers and cladocerans of the zooplankton community. Lakes \& Reservoirs: Research and Management, 2002, 7: 87-92.

[4] Garcia PR, Nandini S, Sarma SSS et al. Seasonal variations of zooplankton abundance in the freshwater reservoir Vallo de Bravo(Mexico). Hydrobiologia, 2002, 467: 99-108.

[5] 日本生态学会环境问题专门委员会. 环境和指示生物(水域分册). 北京: 中国环境科学出版社, 1987: 69-98.

[6] 沈暳芬，章宗涉，龚循矩等. 微型生物监测新技术. 北京：中国建筑工业出版社, 1990: 126-134.

[7] Harper D. Eutrophication of freshwaters: principles, problems and restoration. London: Chapaman and Hall, 1992: $120-127$.

[8] 金湘灿, 屠清瑛编. 湖泊富营养化调查规范. 北京: 中国环境科学出版社, 1990.

[9] 章宗涉, 黄祥飞. 淡水浮游生物研究方法. 北京: 科学出版社, 1991.

[10] 王家楫. 中国淡水轮虫志. 北京: 科学出版社, 1961: 1-288.

[11] 蒋览治, 堵南山. 中国动物志(淡水枝角类). 北京: 科学出版社, 1979: 1-297.

[12] 中科院动物所甲壳动物研究组编著. 中国动物志(淡水桡足类). 北京: 科学出版社, 1979: 1-450.

[13] 谭 镇, 钟 萍, 应文晔等. 惠州西湖底泥中氮磷特征的初步研究. 生态科学, 2005, 24(4): 318-321.

[14] Sommer U ed. Plankton Ecology, succession in plankton communities. Berlin: Spring-Verlag, 1989: 253-296.

[15] Dussart BH, Fernando CH, Matsumura-Tundisi T et al. A review of systematics, distribution and ecology of tropical freshwater 
zooplankton. Hydrobiologia, 1984, 113: 77-91.

[16] Dumont HJ. Biogeography of rotifers. Hydrobiologia, 1983, 104: 19-30.

[17] Fernando CH, Zankai NP. The rotifera of Malaysia and Singapore with remarks on some species. Hydrobiologia, 1981, 78: 205-219.

[18] Segers H. Zoogeography of the Southeast Asian Rotifera. Hydrobiologia, 2001, 446/447: 233-246.

[19] Segers H, Dumont HJ. 102+rotifer species(Rotifera: Monogononta)in Broa reservoir(SP., Brazil)on 26 August 1994 with the description of three new species. Hydrobiologia, 1995, 316: 183-197.

[20] Jose de Paggi S. Diversity of Rotifera(monogononta)in wetlands of Rio Pilcomayo National Park, Ramsar Site(Formosa, Argentina). Hydrobiologia, 2001, 462: 25-34.

[21] Gillooly JF, Dodson SI. Latitudinal patterns in the size distribution and seasonal dynamics of new world, freshwater cladocerans. Limnol Oceanogr, 2000, 45: 22-30.

[22] Hall DJ, Threlkeld ST, Burns CW. The size-efficiency hypothesis and the size structure of zooplankton communities. Annual Review of Ecology and Systemutics, 1976, 7: 177-208.

[23] Korponai J, Matyas K, Paulovits G. The effect of different fish communities on the cladoceran plankton assemblages of the Kis-Balaton Reservoir, Hungary. Hydrobiologia, 1997, 360: 211-221.

[24] Swiercowski A, Godlewska M, Poltorak T. The relationship between the spatial distribution of fish, zooplankton and other environmental parameters in the Solina reservoir, Poland. Aquat Living Resour, 2000, 13: 373-377.

[25] Domaizon I, Devaux J. Impact of moderate silver carp biomass gradient on zooplankton communities in a eutrophic reservoir. Consequences for the use of silver carp in biomanipulation. Life Sciences, 1999, 322: 621-628.

[26] Nogueira MG. Zooplankton composition, dominance and abundance as indicators of environmental compart-mentalization in Jurumirim Reservoir(Paranapanema River ), Sao Paulo, Brazil. Hydrobiologia, 2001, 455: 1-18.

[27] Korponai J, Paulovits G, Matyas K. Long-term changes of cladoceran community in a shallow hyper-trophic reservoir in Hungary. Hydrobiologia, 2003, 504: 193-201.

[28] Bachmann RW, Horsburgh CA, Hoyer MV et al. Relations between trophic state indicators and plant biomass in Florida lakes. Hydrobiologia, 2002, 470: 219-234.

[29] Maemets A. Rotifers as indicators of lake type in Estonia. Hydrobiogia, 1983, 104: 357-361

[30] Sladecek V. Rotifers as indicators of water quality. Hydrobiogia, 1983, 100: 169-202.

[31] 李明德. 天津轮虫出现时期和水质评价[水生生物学论文集]. 北京: 海洋出版社, 1991: 168-177. 